\title{
Políticas de planejamento turístico e ordenamento de território - a influência dos cruzeiros marítimos no espaço turístico de Porto Belo - SC
}

\author{
Politics of tourist planning and order of territory - the influence of the sea cruises \\ in the tourist space de Porto Belo - SC
}

\author{
Marina Wöhlke Cyrillo (CYRILLO, M. W.) *
}

\begin{abstract}
RESUMO - A interpretação dos processos necessários de planejamento turístico e ordenamento de território, à luz da abordagem sistêmica do turismo e no paradigma da sustentabilidade das destinações é tratada neste artigo a partir de dados resultantes de pesquisa bibliográfica e pesquisa de campo, no município de Porto Belo situado no litoral de Santa Catarina a $60 \mathrm{~km}$ da capital (Florianópolis). O objetivo central deste trabalho foi refletir sobre a influência dos fluxos turísticos de cruzeiros marítimos (somados à demanda de turismo de praia e veranistas) e as conseqüências impactantes desta relação na destinação. Pode-se concluir que o receptivo de cruzeiros marítimos está em ascensão na oferta de serviços turísticos de Porto Belo, tornando-se necessário o fortalecimento deste setor a partir da estruturação de sua infra-estrutura básica e turística.
\end{abstract}

Palavras-chave: Espaço turístico; Cruzeiros marítimos; Planejamento turístico; Ordenamento territorial.

ABSTRACT - The interpretation of the necessary processes of tourist planning and order of territory, to the light of the systems analysis of the tourism and in the paradigm of the sustentabilidade of the destinations is dealt with in this article from resultant of bibliographical research and research field, in Porto Belo situated in the coast of the 60 Santa Catarina, $60 \mathrm{~km}$ of the capital (Florianópolis). The central objective of this work was to reflect the impactantes influence of the tourist flows of sea cruises (added to the demand of tourism of beach and people who lives in second residence) and consequences of this relation in the destination. It can be concluded that the receptive one of sea cruises is in ascension in offers of tourist services of Porto Belo, becoming necessary the strengthening of this sector from the improvement of its basic and tourist infrastructure.

Key words: Touristic space; Sea cruises; Touristic planning; Territorial ordainment.

\footnotetext{
* Bacharel em Turismo e Hotelaria (2001), Especialista em Planejamento e Marketing do Turismo (2003) e Mestre em Turismo e Hotelaria (2005) pela Universidade Vale do Itajaí - UNIVALI. Docente do curso de graduação em Turismo da Faculdade Cenecista de Joinville; de pós-graduação latu sensu em Consultoria e Planejamento do Turismo - UNIVALI e do curso de pós-graduação latu sensu em Planejamento Turístico da Universidade do Contestado - UNC. Consultora da Cyrillo Tourism Consulting. Endereço: Rua Inácio Bastos, 96 (apto 601-A) - Ed. Caribe - Bucarein; Joinville/SC. CEP: 89202-310. Telefones: (047) 3026-7078 // Fax : (047) 3261-1204 // Celular : (047) 9607-2727. E-mail: marinawc@uol.com.brou marinaw@univali.br
} 


\section{INTRODUÇÃO}

Tratar do turismo na geografia pressupõe ação de pesquisa integrada a modelos de percepção do espaço físico além das suas atribuições sensoriais, perpassando também pelo seu aproveitamento - "função". Os espaços turísticos que se modificam ao longo do tempo por um processo natural de transformação (natural não somente pelas questões físico-químicas, mas natural pelo processo cultural de evolução humana) tendem a receber dada a característica multifuncional do turismo, uma série de impactos (positivos e negativos) e suas conseqüências (efeitos) advêm de causas não consideradas ou consideradas parcialmente no processo de planejamento, tais como influências no meio ambiente ecológico, social, econômico, político e cultural.

Neste sentido, o planejamento turístico numa visão sistêmica é tecnicamente abordado não somente nos seus limites organizacionais / de gestão (superestrutura) como também nos seus aspectos físico-espaciais (infra-estrutura e ocupação/distribuição) para dar o suporte necessário às leis de mercado (relação oferta e demanda turística).

O aprofundamento deste artigo se dá na interpretação dos processos necessários de planejamento turístico e ordenamento de território, à luz da abordagem sistêmica do turismo e no paradigma da sustentabilidade das destinações. Os dados trabalhados de forma qualitativa advêm de resultados de pesquisa bibliográfica e pesquisa de campo, na destinação turística exemplificada - Porto Belo em Santa Catarina, também a partir de vivências no campo do planejamento público deste destino, por parte da pesquisadora.

O objetivo central deste trabalho é refletir sobre a importância das políticas de planejamento turístico e de ordenamento de território numa destinação turística que recebe a influência dos fluxos turísticos de cruzeiros marítimos (somados à demanda de turismo de praia e veranistas) e as consequiências impactantes desta relação na destinação.

O objeto de estudo é o município de Porto Belo situado na chamada Região da Costa Esmeralda, litoral de Santa Catarina a 60 km da capital do Estado (Florianópolis), que possui uma área territorial de aproximadamente $95 \mathrm{~km}^{2}$, com população estimada 
em aproximadamente 13 mil habitantes ${ }^{1}$ (IBGE, 2006). Suas atividades econômicas predominantes são a pesca e o turismo, dada sua localização geográfica privilegiada - de frente ao oceano Atlântico numa tranqüila baía de águas calmas.

A forte influência da cultura de base açoriana, e os atrativos naturais, em especial as praias e a ilha de Porto Belo fortalecem o desenvolvimento do produto turístico local, que apresenta significativo índice de demanda turística nas temporadas de verão, pois o município é corredor de passagem para outro destino consolidado, o município de Bombinhas. Além do fluxo de turistas e veranistas, que contribuem para um aumento significativo da população (flutuante, neste caso), desde 1998 o município recebe a visita de navios de cruzeiros marítimos, com demanda média de 1.200 passageiros por navio/dia, chegando, muitas vezes a receber simultaneamente dois a três navios, segundo informações do órgão oficial de turismo no município, contidas no Relatório de Demanda Turística de Porto Belo, da Secretaria Municipal de Turismo de Porto Belo (2008)

$\mathrm{O}$ turismo ocupa internacionalmente o ranking das atividades econômicas que mais movimenta a economia de países, regiões e localidades, cuja forte atratividade, de ordem natural ou cultural, estimula o fluxo de demanda. Segundo a Organização Mundial de Turismo (2004), a atividade é responsável pela geração de 6 a 8 por cento do total de empregos no mundo.

Analisando de forma sistêmica, o desenvolvimento do turismo em um núcleo receptor precisa, além da execução das políticas públicas próprias para a atividade, da estruturação de serviços e equipamentos básicos e turísticos - o que compõem a oferta de um produto; a previsão e captação de demanda; o ordenamento do marketing institucional bem como a execução constante de ações que beneficiem o ambiente ecológico, econômico, cultural e social de uma destinação. Todos estes fatores são importantes para o desenvolvimento sustentável das comunidades, mais ainda quando somadas à sua população estão os fluxos turísticos. A preocupação central deste artigo está em considerar sobre as ações necessárias de planejamento e ordenamento de território para o destino que, além dos fluxos constantes de turistas e veranistas, recebe outro fluxo, neste caso diário, de cruzeiros marítimos, a cada temporada de verão (Dezembro a Março).

1 Dados do IBGE 2006 - Caracterização dos municípios catarinenses. Disponível em: <http://www.ibge.gov.br>. Acesso em junho de 2008. 


\section{POLÍtTICAS DE PLANEJAMENTO TURÍSTICO E ORDENAMENTO DE TERRITÓRIO - NECESSIDADES ESSENCIAIS NO DESENVOLVIMENTO TURÍSTICO DE UM MUNICÍPIO LITORÂNEO DE PEQUENO PORTE}

A organização do espaço geográfico pressupõe medidas de planejamento (plano de desenvolvimento e monitoramento da atividade turística) que possam transformar o meio ambiente sem os impactos que o saturem ou degradem ao longo dos tempos. Esta transformação pressupõe o uso e as funções que o ser humano dá para cada região. Estas medidas objetivam assegurar o desenvolvimento dos espaços, considerando também todas as alterações na paisagem dos locais, que o processo de urbanização, impulsionado pelo turismo pode causar.

Considera-se, aqui, a paisagem como um sistema geográfico formado pela influência dos processos naturais e das atividades antrópicas configurado na escala da percepção humana, conforme Oliveira (1999).

Com base no avanço do turismo nacional e principalmente pela sensibilização, conscientização e incentivo dado aos municípios pelo Programa Nacional de Municipalização do Turismo (1999) e sua continuidade na formatação de Regiões Turísticas por meio do Programa de Regionalização do Turismo dentro do Plano Nacional do Turismo (2003), estes passaram a se organizar para a atividade turística, na tentativa de incrementar as suas economias e os seus modos de vida.

Desta forma, a idéia de que a ação do homem sobre o espaço vai depender de sua organização social, que por sua vez é determinada pela forma como ele produz os bens necessários para sua subsistência. No entanto, a "opção" pelo desenvolvimento da atividade turística sugere organização e principalmente um planejamento para que os impactos negativos ocorram de maneira mínima nas localidades, prejudicando-as o menos possível. Segundo Boullón,

Planejar bem o espaço é descobrir sem erro como é a realidade (nossa realidade, não outra), e ser capaz de imaginar aquilo que devemos agregar-lhe, para que, sem que perca seus atributos, adapte-se a nossas necessidades. Por isso, uma estrutura lógica é aquela que melhor se adapta a um organismo preexistente, dado pela natureza. Essa é a ordem orgânica. (2002, p. 8) 
Com base nisto, o organismo preexistente ${ }^{2}$ de uma região deverá ser trabalhado de forma a não se perder, nem a história, nem a paisagem natural. Ocorrem transformações - o que Santos (1997) afirma ser natural, pois o espaço está sempre sendo modificado, se não pela ação do homem, pela ação da própria natureza - mas estas transformações devem ser benéficas para a sociedade, garantindo a existência do espaço (natural e urbano), para as gerações futuras. A manutenção dos espaços para as gerações futuras é um dos pressupostos para o desenvolvimento sustentável, e nesta idéia, o turismo deverá ser administrado.

Dentro da metodologia de planejamento de Roberto Boullón, o planejamento físico é caracterizado como

[...] uma técnica que pertence às categorias experimentais do conhecimento científico. Sua finalidade é o ordenamento das ações do homem sobre o seu território, e ocupa-se em resolver harmonicamente a construção de todo tipo de coisas, bem como em antecipar o efeito da exploração dos recursos naturais (2002, p. 72).

O ordenamento físico-espacial do turismo aliado a um processo de planejamento da atividade (gestão) é uma ação muito recente nos planos de governo em geral. O histórico da ocupação dos espaços litorâneos brasileiros, e em especial de Santa Catarina, são marcados por uma dinâmica de exploração muito econômica, ou seja, modelos de gestão do turismo cuja preocupação está exclusivamente nos resultados financeiros que o turismo possa gerar.

É importante destacar que as paisagens brasileiras de litoral são entre as diversas estruturas paisagísticas existentes pelo país afora, as que mais cedo, no processo de construção da nação, sofreram transformações radicais. No início deste século, evidencia-se a situação do processo de urbanização turística de segunda residência, como fator importante de transformação e criação de paisagens ao longo da costa brasileira, especificamente em Santa Catarina, no litoral centro, por comunidades das regiões povoadas e colonizadas no Vale do Itajaí (Blumenau, Brusque, por exemplo).

\footnotetext{
${ }^{2} \mathrm{Na}$ visão de Boullón o organismo preexistente refere-se ao espaço natural e artificial presente antes de qualquer modificação humana direcionada ao fenômeno do turismo.
} 
As alterações no espaço físico do litoral se deram não somente por esta busca de "uma segunda residência" como também para oportunizar uma "exploração econômica" de uma atividade em expansão, a partir da década de 70-80, incrementada ainda mais com a demanda do turismo do MERCOSUL - Mercado Comum do Sul ${ }^{3}$. Nesta década, os gestores públicos das cidades litorâneas nem pensavam ou cogitavam a presença de cruzeiros marítimos na orla, logo, o dimensionamento físico-espacial para o aproveitamento dos espaços de lazer (veraneio), mal foi planejado para o uso turístico menos ainda para a visitação de turistas de cruzeiros.

Os impactos decorrentes de uma ausência de planejamento e ordenamento destas regiões no período de sua urbanização (década de 50 com mais ênfase num crescimento progressivo até os dias atuais) ocasionaram problemas como a erradicação da vegetação nativa, arruamento e destruição de dunas e areias, retificação de riachos, aterramentos de lagoas, inexistência de saneamento básico, falta de acessos e vias planejadas para grandes fluxos integrados (veículos, ciclistas e pedestres) entre outros impactos negativos. Segundo Macedo (2002), os efeitos ambientais são sentidos a médio e em longo prazo com o adensamento urbano, com a impermeabilização do solo, com a constante e exagerada poluição das águas em épocas de temporada.

O processo de ocupação de um local para fins turísticos ocasiona principalmente, uma constante transformação da paisagem, e sempre que se planeja esta mudança, é preciso considerar diversos aspectos, tais como, as características funcionais do suporte físico (uso que se dá a cada estrutura projetada num espaço de uso turístico); as características climáticas do lugar e as diferentes formas e responsabilidades de adaptação das comunidades de seres vivos a essas características (do seu ecossistema); aos valores sociais e culturais bem como os padrões de ocupação do homem neste espaço.

Para que estas questões possam de fato ser consideradas num processo de planejamento é imprescindível a participação de vários atores envolvidos com este cenário em transformação. As decisões de ordem política que interferem diretamente nas decisões que irão subsidiar estas mudanças no espaço e, por conseguinte, na

3 O MERCOSUL - Mercado Comum do Sul é a União Aduaneira (livre comércio intrazona e política comercial comum) de cinco países da América do Sul. Em sua formação original o bloco era composto por quatro países: Argentina, Brasil, Paraguai e Uruguai. Desde 2006, a Venezuela depende de aprovação dos congressos nacionais para que sua entrada seja aprovada. 
paisagem e modelo de vida das populações locais, no caso, litorâneas, devem ser discutidas e analisadas sob diversos ângulos para manutenção de seu valor paisagístico.

Macedo (2002) afirma que o valor paisagístico é aquele atribuído a um local, pelo consenso do todo da sociedade ou de um de seus grupos e que identificam para um desses conjuntos sociais este lugar em relação aos demais. Ainda, reflete-se que podem ser arroladas como qualidades definidoras de valor paisagístico de um determinado espaço os atributos de excepcionalidade, estética e afetividade. Todos esses atributos são muito dependentes do movimento natural de transformação cultural das comunidades, que no século XX foi altamente influenciado pelos meios de comunicação de massa. Estes constantemente criam e recriam padrões estéticos, produzindo e destruindo símbolos e padrões tradicionais e dificultando um processo de caracterização estável e significativo dos valores paisagísticos nacionais.

Cabe ponderar ainda, que a maioria das cidades de onde provêm os veranistas e turistas nacionais também carece da mesma falta de infra-estrutura em muitos dos seus bairros e subúrbios, revelando uma importante contradição: ao mesmo tempo em que nas cidades de origem dos turistas são escassas ou inexistentes áreas de lazer com as qualidades cênicas encontradas na orla ou nos campos, matas e serras, são também ainda incompletas, precárias e deficientes as suas estruturas, como as de água, esgoto e viária. Nas cidades destinadas ao turismo, na orla observam-se as mesmas deficiências de água, esgoto, estrutura viária e outras mais para atender as altas demandas de férias. O ponto importante de análise é a preparação (ou falta dela) das destinações para incrementar ainda mais a sua demanda, a partir do receptivo dos cruzeiros.

O turismo de cruzeiros marítimos é marcado pela forte tendência ao "glamour", à exploração de sensações e motivações no turista de beleza, charme, luxo e elegância. Neste sentido, cruzando as expectativas do mesmo em relação às destinações visitadas ao longo do percurso do navio, atingir aos mesmos padrões de excelência, torna-se o grande desafio.

O planejamento do território a ser "dividido" com os turistas que desembarcam numa destinação é tarefa desafiadora, porque pressupõe a existência de políticas que ordenem e controlem este fluxo de "turistas a mais", além da relação que se estabelece entre "visitante" e "visitado" e do impacto emocional vivenciado pela experiência turística de cada um. 
Geiger (2001) neste sentido coloca que o turismo pode ser o desejo da vivência do espaço e de conhecimento a ele associados. Analisando a ótica da experiência turística de quem a pratica, afirma que

o primeiro ato do turista é o de se "desenraizar, quer seja por "momentos", do local onde vive regularmente, ou rotineiramente. Ao passar por outros lugares, injeta "tolerância e cosmopolitismo, e os gozos de cidadania mundial. Os ricos chegam a reproduzir a circunavegação, em cruzeiros marítimos de luxo.

É pertinente neste sentido lembrar que no início das formações das cidades, toda a estrutura econômica expansionista se dava ao mar. As cidades eram "voltadas" para o mar. Com o avanço tecnológico e com isso a modernização dos meios de transporte, parte deste fluxo intenso se modificou, mas hoje, para o turismo, a exploração dos cruzeiros retoma "o antigo hábito, costume" e evidencia certa tendência a esta modalidade, principalmente no Brasil.

No entanto, mais uma vez o planejamento turístico para este tipo específico de "função" que se dá aos espaços que recebem demanda de cruzeiros, é questionável, se não, inexistente. O turismo e a interrelação com a "espacialidade" traduz uma relação de consumo. Consumo do espaço que direta ou indiretamente o turista faz. É neste aspecto que as comunidades litorâneas precisam se preparar. Preparar-se também não quer dizer moldar-se ao turista, ao atendimento de todas as suas necessidades e interesses, mas sim de atender seus anseios a partir do reconhecimento da atividade, do seu entendimento e acima de tudo da responsabilidade sobre os impactos que a mesma gera.

Silveira (2002) coloca que a interpretação do turismo no processo de ordenamento territorial, enquanto uma prática social e uma atividade produtiva emergente constituem uma realidade em diversos países e regiões, e que, essa realidade cada vez mais se amplia na esfera das políticas institucionais que têm como objetivo estabelecer estratégias de desenvolvimento, tanto no nível regional e nacional, quanto supranacional.

Analisa-se, neste sentido, a importância das políticas locais de desenvolvimento, seja por meio de alianças de desenvolvimento regional, seja por meio da elaboração de Planos Diretores complexos e abrangentes ou mesmo a criação de Planos de Manejo da Atividade Turística em áreas litorâneas, independentes das mesmas serem classificadas como unidades de conservação. 


\section{A INFLUÊNCIA DOS CRUZEIROS MARÍTIMOS NO ESPAÇO TURÍSTICO DE PORTO BELO (SC)}

Ao caracterizar o espaço de Porto Belo, o entendimento do significado do termo "espaço" é fundamental. Santos (1997) define espaço ${ }^{4}$, como uma realidade objetiva, um produto social em permanente processo de transformação.

Este espaço geográfico deve, antes de qualquer reflexão sobre o fenômeno turístico, ser analisado no enfoque espaço-temporal, considerando, por um lado, as características naturais e, por outro, a história como um processo dinâmico ao longo do qual a sociedade se transforma, de forma global, mudando sua economia, sua política, paisagem, cultura e suas relações sociais. Assim, cabe destacar que

Tudo o que existe articula o presente e o passado, pelo fato de sua própria existência. Por essa mesma razão, articula igualmente o presente e o futuro. Desse modo, um enfoque espacial isolado ou um enfoque temporal isolado, são ambos insuficientes. Para compreender qualquer situação, necessitamos de um enfoque espaço-temporal (SANTOS, 1982, p. 205).

A cidade de Porto Belo pode ser interpretada a partir da proposta de Milton Santos, que define o espaço e seus elementos (os homens, as firmas, as instituições, o meio ecológico e as infra-estruturas) e as categorias do método geográfico (estrutura, processo, função e forma).

O espaço em estudo sofreu mudanças culturais, políticas, sociais e físicoespaciais ao longo do tempo, impondo novas funções a cada um dos elementos da sociedade e o fenômeno turístico contribui e muito para este quadro constante de transformações, criando, assim, um novo espaço. Segundo Cruz (2001, p. 34),

o turismo, tal como outras atividades - e concorrendo com elas - introduz no espaço objetos definidos pela possibilidade de permitir o desenvolvimento da atividade. Além disso, objetos preexistentes em dado espaço podem ser igualmente absorvidos pelo e para o turismo, tendo seu significado alterado para atender a uma nova demanda de uso, a demanda de uso turístico.

\footnotetext{
${ }^{4} \mathrm{O}$ espaço é considerado como a condição de ocorrência de fenômenos, não como uma determinação dependente deles, e constitui uma representação a priori que serve de fundamento, de uma maneira necessária, aos fenômenos exteriores (KANT, 1972, p. 66 apud REYNAUD, 1986). Entendido desta forma, o espaço constitui a base física (os alicerces) sobre a qual os diferentes grupos humanos exercem as mais diversas atividades.
} 
Embora a transformação no espaço ainda não seja tão intensa em Porto Belo, com o avanço da atividade turística de receptivo de cruzeiros marítimos, pode-se relacionar esta modificação à aplicação de instrumentos de planejamento sobre o uso do espaço natural e urbano, de forma a minimizar os seus possíveis impactos. Muitos projetos já estão sendo aplicados para que, esta alteração no espaço se produza como forma de investimento e apoio ao turismo receptivo. Destaca-se nestes projetos a organização do trapiche dos pescadores com a construção do novo píer; um trabalho de conscientização turística com a população local a partir da formação escolar; cursos de capacitação e atendimento para os comerciantes e atendentes locais; sinalização turística em toda a cidade e a iluminação adequada dos espaços públicos (Projetos analisados pela Secretaria de Turismo de Porto Belo, 2008).

Segundo informações desta secretaria, o histórico do receptivo de cruzeiros em Porto Belo iniciou em 1998 quando o município recebeu o primeiro transatlântico. O navio Costa Allegra com escala prevista para atracar no píer de Itajaí (cidade portuária a $40 \mathrm{~km}$ ao norte de Porto Belo) precisou desviar sua rota devido a um fechamento do Porto de Itajaí, o que o fez atracar em Porto Belo, e foi neste ano o primeiro contato das empresas com a paisagem turística de Porto Belo e todo o seu espaço. Da mesma forma, o primeiro contato da comunidade autóctone (na sua maioria, pescadores) com o turista de cruzeiros.

Encantados com a enseada de Porto Belo e percebendo o potencial turístico e técnico (para paradas) da cidade, na temporada seguinte, a Costa Cruzeiros passou a dividir suas escalas entre Itajaí e Porto Belo. Nestes primeiros anos (98/99), a baía de Porto Belo recebeu nove paradas dos navios Costa Allegra e Costa Marina; já utilizando as dependências do Iate Clube Porto Belo - espaço privado utilizado como píer de recepção aos cruzeiros, contando com apoio institucional da Secretaria de Turismo, Empreendimento Ilha de Porto Belo e Governo do Estado em todo o receptivo.

Na temporada 1999/2000, a Costa Cruzeiros - já habituada à estrutura disponibilizada para o desembarque de seus passageiros, concentrou todas as suas quinze paradas em Porto Belo. Neste mesmo período foi preciso uma mobilização junto à Receita e a Policia Federal para legalizar a situação alfandegária do local de desembarque. Como Porto Belo não possui estrutura de Porto, a cidade não oferece 
serviços de um escritório alfandegário. Este fator acabou por "complicar" o processo de alfandegamento de navios que transportam passageiros de nacionalidade estrangeira. Iniciaram-se, neste sentido, as discussões em torno de um problema que persiste atualmente na maioria dos locais de paradas de cruzeiros no litoral brasileiro: a ausência de políticas que estruturem o processo de embarque e desembarque de passageiros, o processo de alfandegamento para empresas entre outros assuntos que interferem diretamente nos resultados, principalmente de ordem econômica, nos municípios receptores. A estruturação desta política perpassa primeiramente uma discussão pública e democrática com os envolvidos no processo, seguida da criação de legislação específica para o setor que resultaria na adequação de normas e preceitos que ordenem tal atividade.

A temporada de cruzeiros 2004/2005 recebeu 18 paradas de navios com aproximadamente 18 mil turistas. Assim como nas temporadas anteriores, os navios que chegaram a Santa Catarina vindos da Argentina e do Uruguai foram obrigatoriamente alfandegados nos portos de Imbituba e Rio Grande - RS. (SECRETARIA DE TURISMO DE PORTO BELO, 2008). Este receptivo repercutiu também uma movimentação econômica significativa na cadeia produtiva do turismo da região. Conforme estimativa da SANTUR $^{5}$ nos documentos que apresentam os resultados da pesquisa de demanda em cada temporada, cada turista de cruzeiros gasta em média US\$ 150. Esta estimativa é divulgada e trabalhada como possibilidades de incremento do produto turístico para potencializarão ainda maior destes resultados.

Segundo informações publicadas na pesquisa realizada pelo mesmo órgão em Porto Belo: 17 dólares são gastos por Brasileiros; e 51 dólares por estrangeiros, por dia. Isso significa que o passageiro de um transatlântico internacional gasta 3 vezes mais do que o turista nacional, gasto este que pode ser considerado como indispensável para a movimentação econômica do município de Porto Belo.

$\mathrm{Na}$ estimativa da Secretaria Municipal de Turismo e Iate Clube de Porto Belo por meio do controle de fluxo de passageiros, a demanda de turistas vem crescendo a cada ano, salvo em temporada cuja "perda" de navios devido aos trâmites de

\footnotetext{
${ }^{5}$ A Santur - Santa Catarina Turismo S/A, é uma empresa de economia mista criada em 28 de junho de 1977, que tem como objetivo o fomento e a divulgação da política estadual de turismo, encontrando-se vinculada a Secretaria de Estado de Turismo, Cultura e Esporte. Anualmente, divulga Relatório de Demanda Turística de Santa Catarina.
} 
alfandegamento contribuiu para o decréscimo. Também é destacado por estes órgãos municipais que o perfil do turista vem modificando a cada ano, conforme aponta a pesquisa de perfil de demanda desenvolvida pela Secretaria de Turismo de Porto Belo e apresentada em Relatório Anual. A mudança é avaliada por tal órgão como qualitativa, pois se percebe no comportamento do visitante uma sensibilidade maior às questões ambientais, um respeito mais visível nestes pelos aspectos culturais locais bem como um gasto considerável em produtos e serviços.

QUADRO DE ESCALAS DE CRUZEIROS MARÍTIMOS EM PORTO BELO - SC

\begin{tabular}{|c|r|r|r|}
\hline Temporada & $\begin{array}{c}\text { Número de } \\
\text { escalas }\end{array}$ & Demanda estimada & $\begin{array}{c}\text { Gasto médio estimada em } \\
\text { UR\$** }\end{array}$ \\
\hline $1997 / 1998$ & 02 & 2.180 & $\mathbf{7 4 . 1 2 0}$ \\
$1998 / 1999$ & 07 & 7.700 & $\mathbf{2 6 1 . 8 0 0}$ \\
$1999 / 2000$ & 15 & 16.500 & $\mathbf{5 6 1 . 0 0 0}$ \\
$2000 / 2001$ & 15 & 21.200 & $\mathbf{7 2 0 . 8 0 0}$ \\
$2001 / 2002$ & 29 & 31.100 & $\mathbf{1 . 0 5 7 . 4 0 0}$ \\
$2002 / 2003$ & 20 & 25.100 & $\mathbf{8 5 3 . 4 0 0}$ \\
$2003 / 2004$ & 18 & 23.800 & $\mathbf{8 0 9 . 2 0 0}$ \\
$2004 / 2005$ & 18 & 18.150 & $\mathbf{6 1 7 . 1 0 0}$ \\
$2005 / 2006$ & 25 & 38.961 & $\mathbf{1 . 3 2 4 . 6 7 4}$ \\
$2006 / 2007$ & 34 & 43.471 & $\mathbf{1 . 4 7 8 . 0 1 4}$ \\
$2007 / 2008$ & 35 & 65.600 & $\mathbf{2 . 2 3 0 . 4 0 0}$ \\
Sub total & $\mathbf{2 1 8}$ & $\mathbf{2 9 3 . 7 6 2}$ & $\mathbf{9 . 9 8 7 . 9 0 8}$ \\
$2008 / 2009 *$ & 51 & 114.750 & $\mathbf{3 . 9 0 1 . 5 0 0}$ \\
Total & $\mathbf{2 6 9}$ & $\mathbf{4 0 8 . 5 1 2}$ & $\mathbf{1 3 . 8 8 9 . 4 0 8}$ \\
\hline
\end{tabular}

FONTE: SECRETARIA MUNICIPAL DE TURISMO DE PORTO BELO- SC, ABRIL DE 2008

*Dados previstos, conforme escala já agendada.

**Tomando como base o gasto médio estimado pela SANTUR de UR \$51 a cada turista internacional e UR \$17 nacional que visitam Porto Belo. Cálculo da média = UR\$34.

O que precisa ser analisado é o quanto estes "benefícios econômicos" interferem no "preço" que se paga pelas transformações espaciais que a destinação precisará sofrer com o aumento significativo da demanda. O planejamento territorial local dentro das políticas de desenvolvimento local e regional precisa ser avaliado e suas condições "custo versus benefício" medidas. A alteração espacial que se planeja para Porto Belo a partir dos projetos de revitalização de praças, construção de Terminal de Desembarque de Passageiros e adaptação dos serviços para os turistas, deverá ser acompanhada por políticas de ordenamento e controle de fluxos.

Atualmente o receptivo de cruzeiros ocorre de forma improvisada, estruturas flexíveis são instaladas nos dias de navio (barracas, tendas), serviços de manutenção são 
refeitos (leve paisagismo e ajardinamento; adaptação do trapiche central dos pescadores) e alguns serviços são disponibilizados (atendentes, agências com roteiros turísticos regionais etc.). Por outro lado, o espaço turístico de Porto Belo é dividido com o da Ilha de Porto Belo, atrativo visitado através de acesso direto do navio. Por se tratar de empreendimento privado, onde existe um controle rigoroso da capacidade de carga, o gerenciamento deste fluxo turístico ocorre de maneira coerente e adequada.

Interpretando os estudos de Butler (1980), as destinações atravessam um ciclo evolutivo semelhante ao ciclo de vida de um produto (no qual as vendas crescem à medida que o produto evolui em estágios de lançamento, desenvolvimento, maturidade e declínio). A forma da curva irá variar, dependendo de fatores como: taxa de crescimento; acesso; diretrizes governamentais; tendências de mercado; destinações concorrentes.

A crescente demanda apontada no quadro acima faz destacar a urgência de políticas de ordenamento de território e fluxo turístico, para que o ciclo de vida da destinação "Porto Belo" não entre no processo de estagnação de forma acelerada.

\section{CONSIDERAÇOES FINAIS}

O referencial teórico deste artigo se concretizou na interpretação dos processos necessários de planejamento turístico e ordenamento de território, à luz da abordagem sistêmica do turismo e no paradigma da sustentabilidade das destinações. No entanto, cabe ainda um aprofundamento de tais parâmetros por meio de outras abordagens teóricas, ampliando a discussão da pesquisadora. Os dados trabalhados de forma qualitativa foram fornecidos em grande parte pelo órgão oficial de turismo de Porto Belo, para que este estudo pudesse de certa forma, sistematizar as informações inserindo neste processo um olhar crítico do meio acadêmico. O artigo poderá subsidiar mais pesquisas sobre o tema além de constituir base de dados da própria secretaria.

O objetivo central deste trabalho foi refletir sobre a importância das políticas de planejamento turístico e de ordenamento de território numa destinação turística que recebe a influência dos fluxos turísticos de cruzeiros marítimos (somados à demanda de turismo de praia e veranistas) e as conseqüências impactantes desta relação na 
destinação, o que se conclui que o receptivo de cruzeiros marítimos é um setor em ascensão na oferta de serviços turísticos de Porto Belo, portanto, toda a estruturação que se faz necessária, permeia este objetivo central: fortalecer este setor, que qualifica a demanda atual e oportuniza um turismo de baixo impacto à comunidade, dado a permanência dos turistas (média de 12 horas) e o tipo de atividades que os mesmos desenvolvem na sua "experiência turística" (passeios, compras, contemplação).

Para que esta experiência turística seja proporcionada de maneira profissional pela comunidade local, o planejamento da infra-estrutura básica e turística do município de Porto Belo precisa sofrer alterações constantes. Na infra-estrutura básica, estão inseridas as legislações que beneficiem a localidade por meio de um ordenamento territorial; do manejo sustentável dos recursos naturais para estruturação dos equipamentos e instalações entre outras de ordem trabalhista, fiscal, sanitária etc. A estruturação das vias de acesso, sinalização e adequação dos serviços básicos são deveres do poder público, em parceira com a comunidade.

A infra-estrutura turística para este segmento - receptivo de cruzeiros marítimos - pressupõe instalações de qualidade (arquitetura e designs dos estabelecimentos adequados à paisagem local; estruturas higiênicas e bem monitoradas nos aspectos de segurança; serviços básicos eficientes bem como qualificação dos recursos humanos), que ordenem o fluxo de demanda turística da localidade (com sinalização eficiente e estratégias de comercialização de forma a beneficiar todos os estabelecimentos) alimentando a cadeia produtiva do turismo local, com ações estratégicas de comercialização e venda do produto turístico "Porto Belo".

As destinações de forte influência paisagística e/ou dotadas de considerável patrimônio cultural tendem naturalmente a aumentar o fluxo de turistas, que motivados por diversos fatores de ordem subjetiva, investem significativos valores em busca da realização de suas expectativas por meio da experiência turística.

Neste sentido, as políticas públicas contextualizadas em uma comunidade hospitaleira e empreendedora, fazem do turismo um fenômeno capaz de enriquecer a sociedade por meio da instalação de equipamentos e serviços; promover a inclusão social quando oportuniza a manifestação cultural e autenticidade da comunidade local por meio da valorização de sua cultura - patrimônio do povo. Ainda, o turismo, se planejado com ações responsáveis diante dos limites sustentáveis de preservação e 
conservação ambiental, tende a projetar um desenvolvimento local para as gerações futuras.

No caso de Porto Belo, as políticas de turismo precisam almejar o desenvolvimento do turismo de forma sustentável, priorizando a valorização dos aspectos culturais da comunidade (cuja cultura de base açoriana é a predominante) bem como o respeito ao patrimônio natural (praias, recursos hídricos, mata atlântica de encosta; manguezais entre outros). O turismo, neste caso, poderá promover o desenvolvimento da sociedade de maneira a impactar muito mais positivamente, minimizando, com as políticas definidas, os impactos negativos típicos do turismo.

\section{REFERÊNCIAS}

BOUllón, R. C. Planejamento do espaço turístico. Trad. Josely Vianna Baptista. Bauru: EDUSC, 2002.

BRASIL. EMBRATUR. PROGRAMA NACIONAL DE MUNICIPALIZAÇÃO DO TURISMO (1999).

BRASIL. Ministério de Turismo. Plano Nacional de Turismo. 2003-2007.

BRASIL. Ministério de Turismo. Plano Nacional do Turismo. 2007-2010.

BUTLER 1980. Ciclo de vida de um produto turístico. In: SANCHO, A. Introdução ao turismo. Trad. Dolores Martin Córner. São Paulo: Roca, 2001.

CRUZ, R. C. A. Políticas públicas de turismo no Brasil: significado, importância, interfaces com outras políticas setoriais. In: SOUZA, M. J. (org.). Políticas públicas e o lugar do turismo. Brasília: Universidade de Brasília; Departamento de Geografia; Ministério do Meio Ambiente, 2001.

Introdução à geografia do turismo. São Paulo: Roca, 2001.

GEIGER, P. P. Turismo e espacialidade. In: RODRIGUES, A. B. (org.). Turismo e geografia: reflexões teóricas e enfoques regionais. 3. ed. São Paulo: Hucitec, 2001.

IATE CLUBE DE PORTO BELO. Relatório de Fluxo de passageiros temporada 20072008. Porto Belo - SC.

IBGE - Instituto Brasileiro de Geografia e Estatística. Banco de dados em cidades. Dados do levantamento em Porto Belo - 2006. Disponível em: <http://www.ibge.gov.br>. Acesso em junho de 2008. 
MACEDO, S. S. Paisagem, turismo e litoral. In: Turismo e paisagem. São Paulo: Contexto, 2002, p. 181-211.

OLIVEIRA, J. Aula ministrada para o Mestrado em Turismo e Hotelaria. Disciplina de ocupação e ordenamento dos espaços para o turismo. Balneário Camboriú: Universidade do Vale do Itajaí, 1999.

OMT. Proyecto de Libro Blanco - una mirada al futuro del turismo de la mano de la Organización Mundial del Turismo. Outubro de 2004.

REYNAUD, A. A noção do espaço em geografia. In: SANTOS, M.; SOUZA, M. A. (org.). O espaço interdisciplinar. São Paulo: Nobel, 1986, p. 5-23.

SANTOS, M. Espaço e método. 4. ed. São Paulo: Nobel, 1997.

Espaço e sociedade. Petrópolis: Vozes, 1982.

SANTUR 2008. Relatório de Demanda Turística de Santa Catarina.

SECRETARIA DE TURISMO DE PORTO BELO, 2008. Relatório de Demanda Turística.

SILVEIRA, M. A. T. As políticas públicas e a nova configuração territorial do turismo no Brasil. In: SOUZA, M. J. (org). Políticas públicas e o lugar do turismo. Brasília: Universidade de Brasília, Departamento de Geografia. Ministério do Meio Ambiente, 2002.

Recebido em: 05 de agosto de 2008

Aprovado em: 05 de setembro de 2008 